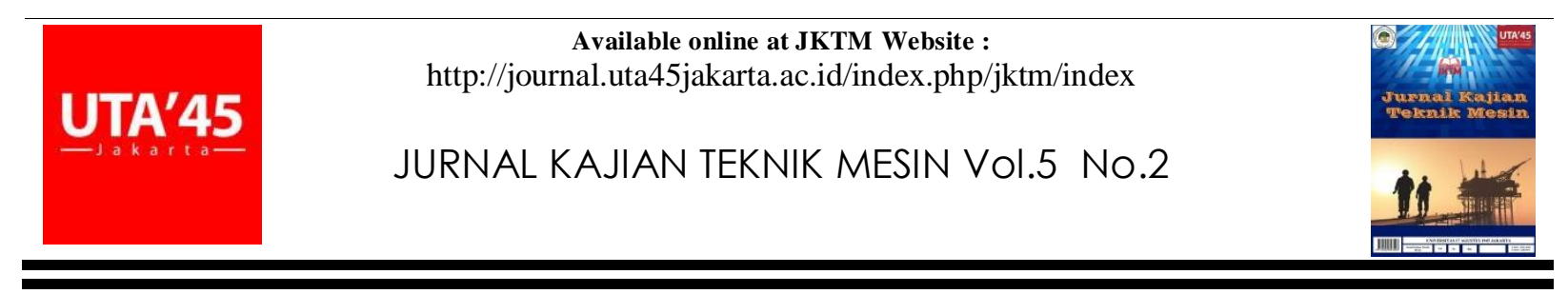

Jurnal Artikel

\title{
Rancang Bangun Alat Pengaduk Dan Pencetak Lontongan Kerupuk Merah
}

\author{
Duskiardi $^{1 *}$, Yovial Mahyoedin ${ }^{1}$, Wenny Marthiana ${ }^{1}$, Sri Wahyuni ${ }^{1}$ \\ ${ }^{1}$ Program studi Teknik Mesin, Fakultas Teknologi Industri, Universitas Bung Hatta \\ *Email: Duskiardi@ymail.com
}

Artkel Info - : Received : 2 Aug 2020; Revised : 28 Aug 2020; Accepted: 31 Aug 2020

\begin{abstract}
Adonan kerupuk merah merupakan campuran dominan tepung dan air yang biasanya diaduk secara tradisional menggunakan tangan. Kajian ini menumpukan perhatian pada rancang bangun alat pengaduk yang dapat memproses adonan secara mekanik. Pada rancang bangun digunakan 2 buah sirip pengaduk yang terpasang dikedua sisi poros dengan putaran motor $1450 \mathrm{rpm}$. Speed reducer mereduksi putaran dengan rasio 1:30. Alat pengadukan adonan juga dilengkapi dengan proses pencetakan yang menggunakan screw sebagai pendorong adonan ke cetakan yang terpasang satu poros dengan sirip pengaduk. Rancang bangun menghasilkan putaran yang dikeluarkan ke poros pengaduk sebesar 24 rpm, yang mampu memproses adonan dalam sekali pengadukan seberat 87,53 kg berupa campuran tepung dengan indukan. Dengan adanya alat pengaduk adonan dan pencetak kerupuk merah ini dapat mengurangai pemakaian waktu dan meringankan kerja operator pada saat produksi. Sehingga dengan menerapkan alat bantu ini dapat meningkatkan jumlah produktivitas sekaligus meningkatkan pendapatan masyarakat.
\end{abstract}

Kata kunci: adonan, kerupuk merah, sirip pengaduk,

\section{Abstract}

The red cracker dough is the dominant mixture of flour and water which is usually stirred traditionally by hand. This study focuses attention on the design of a mixer that can process a dough mechanically. In the design, 2 stirring fins are used which are attached to both sides of the shaft with a motor rotation of 1450 rpm. Speed reducer reduces rotation by a ratio of 1:30. The dough stirring device is also equipped with a molding process that uses a screw to propel the dough to the mold, which is attached to one axis with the mixing fin. The design produces a rotation that is issued to the stirring shaft at 24 rpm, which is able to process the dough in one stirring weighing $87.53 \mathrm{~kg}$ in the form of flour mixture. It is hoped that the benefits from the design of the dough mixer and red cracker molders will reduce time usage and ease the work of the operator during production. So that, by applying this tool can increase the amount of productivity while increasing people's income.

Keywords: dough, red cracker, strirring fins.

\section{PENDAHULUAN}

Kerupuk adalah jenis makanan kecil yang mengalami pengembangan volume dan mempunyai densitas yang rendah selama penggorengan. (Erni dkk, 2016 ). Sebagai suatu produk, kerupuk merupakan bentuk usaha industri rumah tangga yang dapat meningkatkan nilai perekonomian
(Winarno, 2004). Salah satu jenis kerupuk yang diproduksi di pasaran adalah kerupuk merah. Kerupuk merah terbuat dari adonan tepung tapioka, air, garam, pewarna dan lainnya. Kerupuk merah umumnya dijadikan bahan pelengkap makanan sehingga permintaan jumlah produksinya cukup tinggi.

Proses pembuatan kerupuk merah adalah 
dengan cara mencampurkan dan mengaduk adonan menggunakan tangan dengan diputar dan dibalik sampai adonan benarbenar rata. Setelah adonan tercampur kemudian dicetak memanjang berupa lontongan dan lontongan yang telah dicetak akan dikukus selama 6-10 jam. Proses selanjutnya yaitu proses pengirisan lontongan dengan ketebalan $1 \mathrm{~mm}$. Setelah diiris kemudian dijemur dibawah sinar matahari sampai kerupuk benar-benar kering. Proses terakhir adalah pengemasan kerupuk yang kemudian dipasarkan ke konsumen (Wiriano 1984)

Di kota Padang, Provinsi Sumatera Barat, terdapat beberapa industri rumah tangga pengolah kerupuk merah. Dari tahun ke tahun industri rumahan ini memproduksi kerupuk merah dengan menggunakan cara tradisional dimana pada saat pembuatan adoan dan pencetakan dilakukan secara manual dengan tangan.

Menurut Aang Sukendar dkk (2013) perkembangan ilmu pengetahuan dan teknologi mengalami peningkatan yang sangat pesat. Keadaan ini berimbas pada semua bidang kehidupan manusia. Salah satunya adalah bidang industri kecil.

Oleh karena itu, penelitian ini bertujuan merancang alat pengaduk adonan sekaligus sebagai pencetak lontongan kerupuk merah yang dapat meningkatkan kualitas dan kuantitas produksi kerupuk merah. Penerapan rancangan diharapkan dapat meringankan kerja dan membantu pengrajin kerupuk merah dalam meningkatkan produksi untuk memenuhi permintaan konsumen.

\section{METODOLOGI PERANCANGAN}

Diagram alir perancangan ditunjukkan pada gambar 1. Dimensi semua komponen mekanik yang dirancang didasarkan pada input perancangan, yaitu berat/massa adonan yang akan diproses.

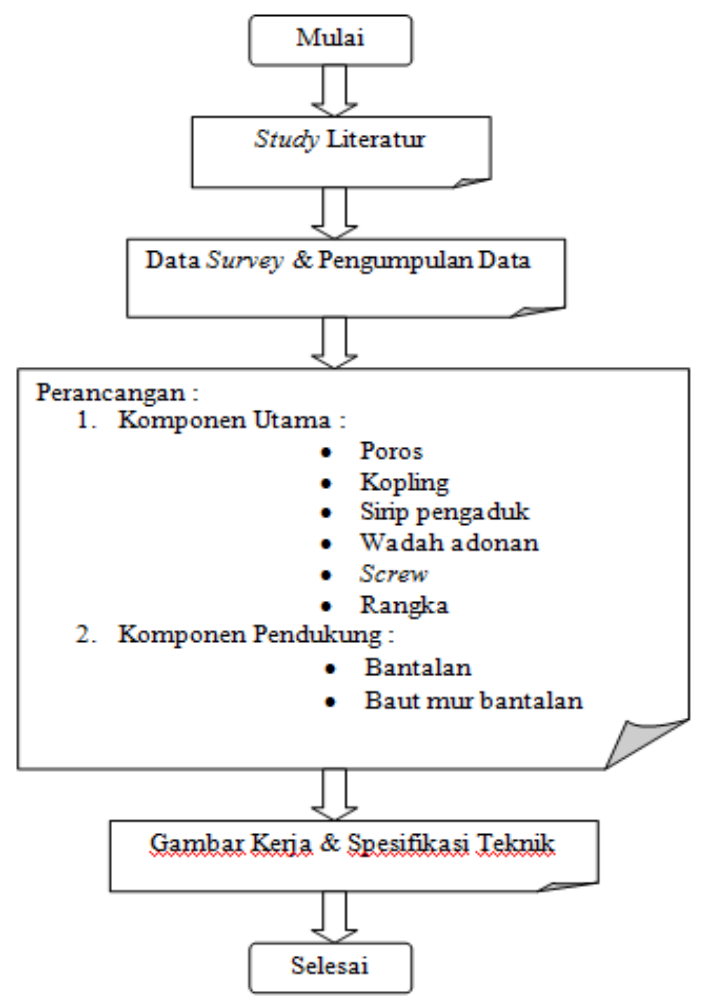

Gambar 1. Diagram alir perancangan

Rancangan alat pengaduk adonan dan pencetak lontongan kerupuk merah terlihat pada gambar 2 .

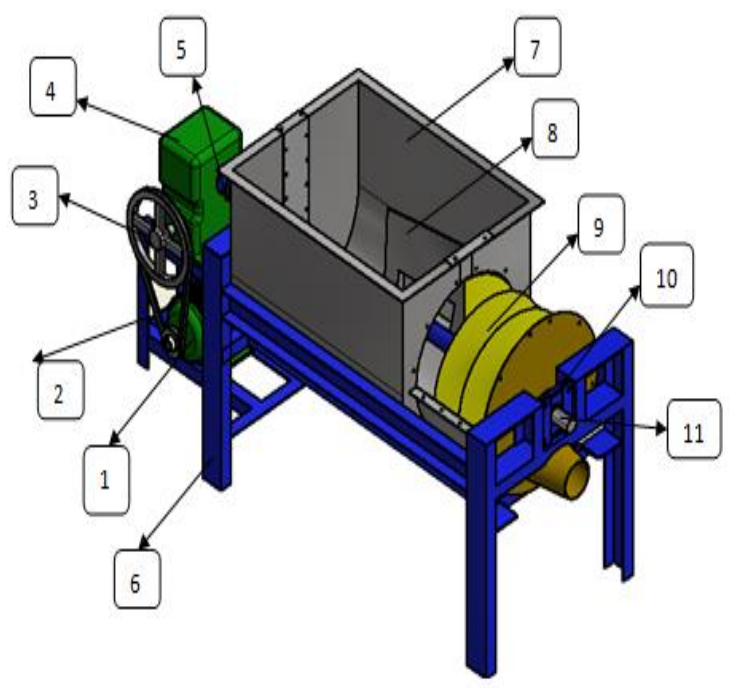

Gambar 2. Alat Pengaduk Adonan dan Pencetak Lontongan

dimana:
1. Motor
7. Wadah
2. Sabuk
8. Sirip
3. Pulley
9. Screw
4. Gear Box
10. Bantalan
5. Kopling
11. Poros
6. Rangka 
Perancangan komponen alat pengaduk, penentuan dimensi dan pemilihan material, dilakukan secara teoritis menggunakan beberapa persamaan yang disarankan oleh Sularso dan Suga (2004), Shigley (2008), Khurmi dan Gupta (1982). Perancangan secara grafis dilakukan dengan menggunakan sofware Solidwork.

\section{HASIL DAN PEMBAHASAN}

\subsection{Berat Total Adonan}

Penelitian yang dilakukan Loli (2018) memberikan komposisi bahan dalam bentuk persentase air dan tepung, masingmasing adalah $16,7 \%$ dan $83,3 \%$. Untuk 1 kali proses pengadonan tepung yang digunakan adalah $75 \mathrm{Kg}$, maka berat total bahan yang akan diaduk adalah 87,53 Kg.

\subsection{Perencanaan Daya}

Rancangan menggunakan dua sirip, seperti terlihat pada gambar 3 .

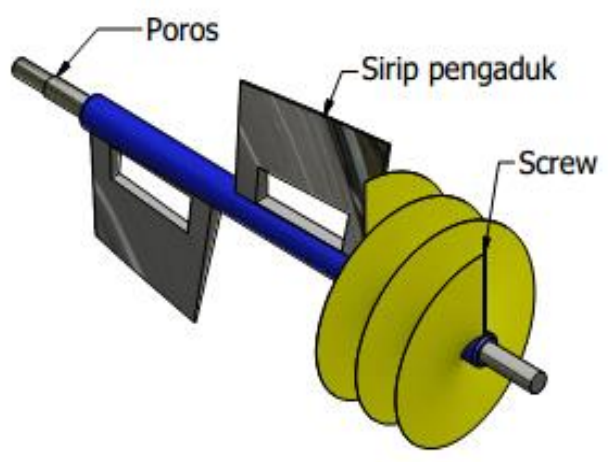

Gambar 3. Poros, sirip pengaduk dan screw pendorong adonan

Gaya yang bekerja pada satu sirip adalah:

$$
\mathrm{F}=\frac{87,53 \mathrm{Kg}}{2 \text { Blade }}=43,765 \mathrm{Kg}
$$

Dengan andaian sirip bekerja $1 / 2$ dari massa yang diaduk pada drum, maka Torsi:

$$
\begin{aligned}
\mathrm{T} & =(\mathrm{F} 1+\mathrm{F} 2) \cdot \mathrm{r}= \\
& =(43,765+43,765) \mathrm{kg} \cdot 250 \mathrm{~mm} \\
& =21882 \mathrm{Kg} \cdot \mathrm{mm}
\end{aligned}
$$

Daya aktual pengaduk yang dibutuhkan:

$$
\begin{aligned}
\mathrm{P} & =\frac{(T / 1000) \times(2 \pi . \mathrm{n} / 60)}{102} \\
& =\frac{\left(\frac{21882 \mathrm{~kg} \cdot \mathrm{mm}}{1000}\right) \times\left(\frac{2 \times 3,14 \times 24 \mathrm{rpm}}{60}\right)}{102} \\
& =0,54 \mathrm{KW}
\end{aligned}
$$

Dengan analisa yang sama terhadap beban dan dimensi dari rancangan, daya screw diperoleh sebesar 0,28 Kw. Sehingga total daya aktual yang dibutuhkan untuk mengaduk dan mencetak adonan adalah:

$$
\begin{aligned}
\mathrm{P}_{(\text {daya })} & =\text { Daya pengaduk }+ \text { Daya Screw } \\
& =0,54 \mathrm{Kw}+0,28 \mathrm{Kw}=1,1 \mathrm{hp}
\end{aligned}
$$

Dengan memilih faktor koreksi yang sesuai, daya nominal output penggerak adalah:

$\mathrm{Pd}=\mathrm{fc} . \mathrm{P}=2,2 \mathrm{hp}$,

Dari hasil perancangan tersebut dipilih penggerak dari motor listrik dengan daya 3 hp.

\subsection{Bebanan Poros}

DBB poros ditunjukkan pada gambar 4.

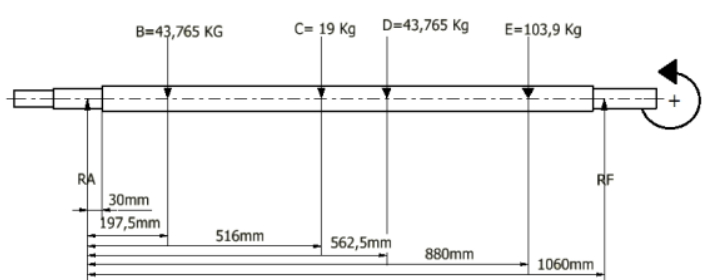

Gambar 4. Momen yang bekerja pada Poros

Dari DBB, momen lentur maksimal pada poros terdapat pada $\mathrm{M}_{\max }=\mathrm{M}_{\mathrm{D}}=$ 30111,1 kg.mm. Tegangan geser maksimum yang terjadi pada poros akibat beban puntir dan momen lentur adalah:

$$
\tau_{\max }=\left(\frac{5,1}{D_{s^{3}}}\right) \sqrt{\left(K_{m} \cdot M\right)^{2}+\left(K_{t} \cdot T\right)^{2}}
$$

Hasil perhitungan menunjukkan bahwa poros aman di pakai, karena $\tau_{\max }<\tau_{a}$

\subsection{Perencanaan Screw}

Screw berfungsi mendorong adonan yang telah kalis untuk dicetak dalam bentuk 
lontongan, dengan dimensi lontongan 10 $\mathrm{cm}$ x $50 \mathrm{~cm}$. Perhitungan tegangan geser pada screw juga aman dipakai karena menghasilkan:

$$
\tau_{g}=\frac{16 \times T}{\pi \times d r^{3}}=2,6 \mathrm{~kg} / \mathrm{mm}^{2}<\tau_{a}
$$

dengan $\mathrm{T}=$ Torsi poros $=66581,6 \mathrm{~kg} \cdot \mathrm{mm}$

\subsection{Volume Drum}

Sebagai wadah tempat adonan dengan kapasitas $75 \mathrm{~kg}$, dan tutup screw dirancang menggunakan material stainless steel seperti terlihat pada gambar 5 .

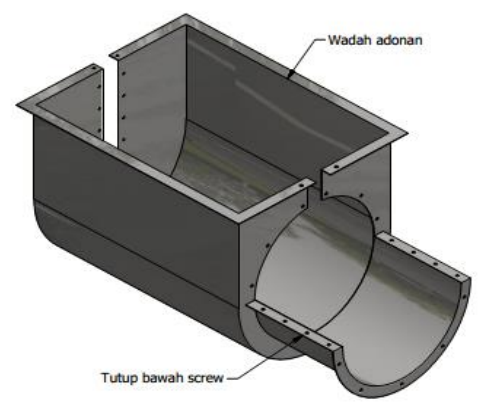

Gambar 5. Wadah adonan

Drum pada saat beroperasi terisi $\pm 60 \%$ dari volume keseluruhan agar adonan tidak tumpah pada saat pengadukan. Dengan menerapkan persamaan kontinuitas, diperoleh volume drum sebesar 247833,3 $\mathrm{cm}^{3}$, dengan kapasitas adonan yang keluar cetakan sebesar $3,3 \mathrm{~kg} / \mathrm{s}$, dan kecepatan $0,64 \mathrm{~m} / \mathrm{s}$.

\subsection{Perancangan Kopling}

Untuk menghubungkan poros pengaduk dengan speed reducer dirancang sebuah kopling cakar seperti pada gambar 6 . Kopling yang direncakan mempunyai 4 buah pion berbentuk silinder.

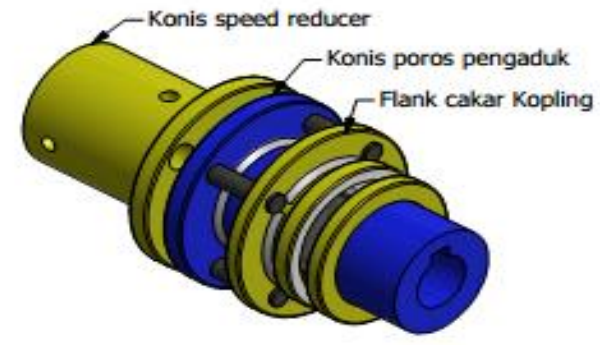

Gambar 6. Kopling cakar

\subsection{Perancangan Komponen lain}

Berdasarkan jenis pembebanan dan besarnya torsi yang terjadi maka dipilih bantalan yang menumpu poros yaitu jenis Plummer SY 40 TF. Dari analisa yang dilakukan, bantalan ini mampu bekerja selama 6004 jam kerja.

Penggerak yang dipilih motor listrik dengan daya 3 HP. Putaran yang dipakai $1450 \mathrm{rpm}$, direduksi oleh speed reducer dengan rasio 1:30. Menggunakan pulley sebagai penghubung putaran dari motor ke speed reducer dengan diameter pulley output 4 inchi dan diameter input speed reducer 8 inchi.

\subsection{Perancangan Dudukan}

Dudukan dari semua komponen dirancang rangka menggunakan material baja dengan profil U seperti gambar 7 berikut:

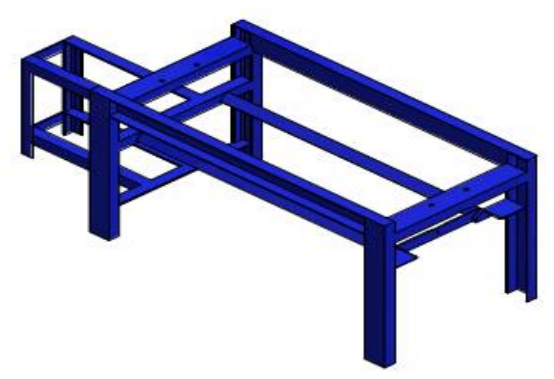

Gambar 7. Rangka dudukan

\section{KESIMPULAN}

1. Dimensi alat pengaduk adonan dan pencetak lontongan kerupuk merah

- Panjang $1600 \mathrm{~mm}$

- Lebar $600 \mathrm{~mm}$

- Tinggi $900 \mathrm{~mm}$ 
2. Penggerak motor listrik 1 phasa

- Daya 3 HP

- Putaran $1450 \mathrm{rpm}$

3. Wadah pengadukan adonan dan tutup screw menggunakan plat stainless steel dengan ketebalan $2 \mathrm{~mm}$. Kapasitas sekali pengadukan $75 \mathrm{~kg}$ tepung.

4. Kapasitas alat sebesar $225 \mathrm{~kg}$ tepung /jam

\section{DAFTAR PUSTAKA}

Listijorini E., Aswata, Aditya D. S. 2016. Perancangan Mesin Pembuat Pola Kerupuk dengan Kapasitas 1500 kerupuk Per 4 Jam. Cilegon: Universitas Sultan Ageng Tirtayasa.

Winarno, F.G. 2004. Kimia Pangan dan Gizi, Gramedia Pustaka Utama. Jakarta.

Wiriano, H. 1984. Mekanisme Teknologi Pembuatan Kerupuk. Balai
Pengembangan Makanan Phytokimia. Badan Penelitian dan Pengembangan Industri, Departemen Perindustrian, Jakarta.

Kurniawati Loli. 2018. Perancangan Alat Pengaduk Adonan Kerupuk Merah Kapasitas 75 KG. Padang: Universitas Bung Hatta.

Khurmi, r.s and J.K. Gupta. 1982. A text Book of Machine Design. Ram NagarNew Delhi. Eurasia Publishing House.

Priyanto, S. (2017). Rancang Bangun Drum Oven Mesin Pengering Limbah Ikan untuk Pakan Ternak. Jurnal Kajian Teknik Mesin, 2(2), 128-132.

Shigley's, 2008. Mechanical Engeneering Design Ninth Edition. New York: The McGraw-Hill Companies.

Suga kiyokatsu dan Sularso, 2004. Dasar Perencanaan dan Pemilihan Elemen Mesin. Jakarta, Pradnya Paramita. 